\title{
HOMBRES DE LETRAS: EL PENSAMIENTO POLÍTICO SOCIAL DEL MÉXICO POSREVOLUCIONARIO
}

\author{
Adrián Gurza Lavalle \\ Doutorando - FFLCH/USP
}

\begin{abstract}
RESUMO: Homens de letras foram quase todos os intelectuais mais importantes do pensamento político social do México pós-revolucionário: literatos, ensaístas, nacionalistas de diversos nacionalismos e revolucionários de uma maneira que pouco tem a ver com as convicções revolucionárias do resto da América Latina. As páginas deste artigo tentam fornecer ao mesmo tempo um panorama e uma interpretação geral dessa tradição intelectual, baseando-se na identificação de determinantes de longo prazo que foram herdadas tanto do processo de construção nacional como da revolução de 1910, que deu origem ao Estado moderno mexicano. O texto assinala algumas das especificidades principais sobre as quais se poderia refletir para compreender as diferenças entre a tradição intelectual mexicana e a brasileira.

ABSTRACT: Mexico has a long tradition of political and social thinkers. This article is, at the same time, a general view of Mexico's post-revolutionary intelligentsia and an attempt to explain its most singular characteristics in a scope of long term determinations. These determinations were part of the heritage of the independence and national processes and they also go through the 1910's revolution, ending with the consolidation of the post-revolutionary State. The article highlights some of the peculiarities that differentiate the Mexican intellectual tradition from the Brazilian one.
\end{abstract}

PALAVRAS-CHAVE: México, intelectuais, pensamento, intelligentsia, gerações.

KEYWORDS: Mexico, intellectuals, thought, intelligentsia, generations.

Hombre de letras es una antigua expresión que distingue a su portador del común de los mortales, envolviéndolo en un halo metropolitano y cosmopolita, en una cierta sabiduría y agudeza en el mirar que desborda y hasta desprecia las clasificaciones de los pensamientos y saberes especializados; el hombre de letras anima una reflexión fuera de la academia o de la política, que no es ni aspira a ser antiacadémica o antipolítica, sino que se endereza más bien hacia una poligrafía comprometida con el universalismo y se 
reconoce y desenvuelve confortablemente en la literatura como un reino privilegiado de la herencia cultural con la que dialoga y a la que cultiva. Hombres de letras han sido en el siglo XX los que encarnaron y encarnan el pensamiento político social mexicano que ha permeado el mundo de las ideas más profundamente y en sectores más vastos de la sociedad. No se trata apenas de una peculiaridad propia de los pensadores mexicanos de comienzos del siglo en los que, al igual que en la mayoría de sus pares latinoamericanos, el pensamiento académico disciplinario o político se encontraba escasamente diferenciado del ensayismo filosófico o histórico, según cánones de elaboración que hoy tendrían poco de rigor histórico o filosófico; se trata de una tradición renovada a lo largo del siglo en nombres que comienzan con Alfonso Reyes o José Vasconcelos, que encuentran vuelos de altura incuestionable en las plumas de Octavio Paz o Carlos Fuentes y que desarrollaron el registro más amplio y mordaz de la vida cultural de la nación en las crónicas de un Salvador Novo o de un Carlos Mosiváis ${ }^{1}$.

Esta peculiaridad del pensamiento político social mexicano da pie para intitular sugerentemente este trabajo, pero no es, obviamente, ni la única ni la principal y remite a la intención del presente intento por bosquejar a grandes pinceladas un panorama que sólo por su carácter aproximativo y general puede delinear en un gran movimiento lo que con mayor detalle es una geografía accidentada y difícilmente sistemati$z_{\text {zable }}^{2}$. Aún las obras que en este terreno han merecido más reconocimiento y reediciones se distinguen

\footnotetext{
${ }^{1}$ Esta tradición se ve continuada, no siempre con la misma fortuna o calidad, en la obra literaria de miembros relativamente más jóvenes del pensamiento político social mexicano como José Woldemberg, Reyes Heroles (jr.), Paco Ignacio Taibo II o Héctor Aguilar Camín. Mayor impacto han alcanzado las novelas de este último, particularmente Morir en el Golgo y La guerra de Galio.
}

por su índole confesamente preliminar. Sin embargo, en este caso se cuenta con una ventaja de la que normalmente no gozan los que, como especialistas nativos, dedican sus días a escudriñar con su pensamiento el pensamiento de los otros, sus homólogos nacionales, y a través de éste la historia de México. Se trata de un público lector diferente, no mexicano y más específicamente brasileño, y por lo tanto de un ojo predispuesto para encontrar diferencias con respecto a las singularidades del pensamieno político social de este país, que motiven una reflexión con un mirar distinto sobre lo que sin otro espejo podría ser considerado lugar común u obviedad. Toda ventaja suele acarrear costos del otro lado de la moneda, en este caso, la fortuna de contar con un público diferente se contrapesa con la distancia desde la cual se redactaron estas líneas, esto es, con una fuerte limitación de referencias disponibles y de datos satisfactoriamente completos sobre éstas - lo que ya dice algo sobre la naturaleza de las relaciones culturales entre México y Brasil. Pese a la desventaja, se ha tratado de incluir un número de referencias suficientes para orientar al lector en materia de las principales obras y autores que componen el panorama del pensamiento político social mexicano, y se ha preferido abusar del sistema de notas al pié para redondear la visión sobre dichas obras y autores que, en el cuerpo del trabajo, irán apareciendo sin espacio ni condiciones para su tratamiento pormenorizado. La proliferación de notas de referencia al pié, en demérito de la economía del sistema de citas en el cuerpo del trabajo, obedece a fines peda-

\footnotetext{
${ }^{2}$ Para un análisis sistemático y especializado sobre el pensamiento político social del México posrevolucionario, puede consultarse con provecho el trabajo de Abelardo Villegas, Autognósis: el pensamiento mexicano en el siglo XX (1985). Para una visión más apegada al ámbito de la cultura, consúltese el extenso y atractivo ensayo de Carlos Mosiváis, "Notas sobre la cultura mexicana en el siglo XX" (1976).
} 
gógicos y quien no persiga más propósito que la curiosidad puede prescindir de ellas.

Contribuir, así sea mínimamente, al mejor conocimiento de México en Brasil y estimular de manera comparada la interpretación de esa enorme realidad que llamamos latinoamérica - que pocas preocupaciones suele sucitar por estos lares -, es el mejor servicio al que pueden aspirar las páginas que dan cuerpo a este trabajo. Para tal fin, se organiza la exposición en tres apartados, el primero abocado a dar cuenta de algunos hechos fundantes que como un sustrato de larga duración determinaron la cosmovisión nacional que alimentó y alimenta al pensamiento mexicano y que desde sus orígenes lo diferencia de aquellos pertenecientes a realidades en las que, como en Brasil, el entramado de la nación encontró otros caminos para resolverse. El segundo se orienta al abordage de lo que podría denominarse, echando mano de una frase ya conocida, como la sombra de la revolución mexicana $^{3}$, es decir, los efectos de ocultamiento y organización que ésta proyectó sobre el mundo de las ideas y sobre los hombes y hábitos que lo pueblan; no es preciso insistir en que el sisma histórico de la conflagración de 1910 conjugó a la postre un conjunto de condicionantes que dejaron una huella indeleble en el pensamiento político social mexicano, singularizándolo frente al de otros países de América Latina. Sin duda, la relación entre intelectuales e institucionalización revolucionaria es uno de los trazos más fascinantes de lo que podría ser llamado como intelligentzia a la mexicana, no obstante, en virtud de las limitaciones de espacio y de un benéfico equilibrio interno del trabajo, resultaria un despropósito, para un esfuerzo de esta naturaleza, es decir, introductorio, prolongar este segundo apartado más alla de los

\footnotetext{
${ }^{3}$ La frase proviene del título de un libro - A la sombra de la revolución mexicana - que alcanzó rápidamente el estatuto de clásico (MEYER y AGUILAR CAMÍN, 1991).
}

propósitos recién referidos. El tema há sido arduamente tratado por autores clásicos en la materia y la referencias serán debidamente proporcionadas. Por último, en el tercer apartado se ofrece un memorial defectuoso y limitado, un recorrido breve por los principales representantes del pensamiento político social mexicano posrevolucionario, con la idea de completar un panorama por fuerza demasiado global, pero del que sea posible extraer, al final del recorrido, algunas características generales que confirieron tonalidad y sabor a los hombres de letras del siglo XX en México.

\section{Y la Nación se Hizo... Mestiza, Progresista, Na- cionalista: Mítica}

Y antes de que la revolución fuera, qué era lo que era la nación mexicana, además de nuevos héroes, nuevas instituciones, nuevos discursos y prácticas políticas, y una flamante mitología que se mantendría en pie durante más de setenta años; qué carga histórica traspasó los umbrales del siglo XX, aunque pocos la vieran detrás del deslumbrante efecto de una revuelta de masas y un orden que parecian recién crearlo todo; qué dilemas, esperanzas y traumas de difícil asimilación heredaron los pensadores posrevolucionarios para rumiarlos de nuevo, para elaborarlos desde otras y las mismas perspectivas ${ }^{4}$. Del piso de la larga duración algunos son los hitos que, pese al parteaguas revolucionario que se pretendía cuasi absoluto, permanecieron y continuaron como fuente de motivaciones, problemas y formas de mirar en el pensamiento político social del siglo XX en México. De hecho, algunas

\footnotetext{
${ }^{4}$ Estas continuidades en el campo de la cultura política y de la moral pública han sido maravillosamente puestas en evidencia en la obra de un joven pensador mexicano, Enrique Escalante Gonzalbo, que consolidó ya un merecido prestigio ( $\mathrm{Cfr}$. ESCALANTE GONZALBO, Enrique 1991).
} 
de sus especificidades se ofrecen ya a la vista en la perseverancia de tales determinantes. La primera, la enorme carga dejada por un pasado precolombino, cuajado de significaciones históricas cuya densidad no fue resuelta sino negada y subyugada por la época colonial; se trata de la pregunta clave - culpabilidades -, desprecios y nostalgias de por medio - por la identidad de los mexicanos, por la mexicanidad o por el espíritu de la patria, de la nación, una vez que ésta emergió a la vida independiente. La segunda, a medias realidad y a medias autoengaño, el mestizage elevado a mito fundante de la unidad nacional, es decir, a punto de partida incuestionable para vislumbrar el horizonte de cualquier futuro posible. Y la tercera determinante general, construida en el siglo XIX con el triunfo político e ideológico de los liberales, la asociación histórica entre nacionalismo, liberalismo y lo que podría denominarse como una política de Estado progresista.

Cuando el 13 de agosto de 1521 cayó por fin la gran Tenochtitlán, abatida por las enfermedades, el hambre y la guerra, se desató un proceso cultural que recorrió todos los caminos posibles y no reparó en medios ni en miedos para construir la hegemonía espiritual del conquistador, su superioridad no sólo material sino humana, intrínseca a su ser y a la civilización que lo produjo ${ }^{5}$. A diferencia de la colonización del territorio que siglos después llevaría el nombre de Brasil, en el que una débil densidad demográfica y cultural hizo posible afirmar la supremacía lusa con las armas y con un siempre bien dispuesto espíritu de aventura en pos de saquearlo todo ${ }^{6}$, en la

\footnotetext{
${ }^{5}$ Este proceso de dominación espiritual, civilizatoria y cosmogónica, se encuentra espléndidamente narrado por los derrotados en la obra de Miguel León Portilla, La visión de los vencidos (1980).

${ }^{6}$ Son bien conocidas las referencias al temperamento personalista y a la ética aventurera de los conquistadores lusos en la obra clásica Raízes do Brasil (HOLANDA, 1995, pp. 31-70).
}

Nueva España se desató un largo proceso de competencia cultural en el que la supremacía del conquistador debía ser afirmada a cualquier precio (TODOROV, 1993). El México surgido de la independencia y aquel emanado de la revolución de 1910 fueron y aún son herederos de una estructura cultural colonial, es decir, de una cosmovisión dual de inferioridad y superioridad, inclusión y exclusión que organizan el universo de significaciones de lo indio-autóctono y de lo hispano-occidental ${ }^{7}$. El sentido y significado de lo indio se impuso como un núcleo de contradicciones difícilmente resoluble, que sin embargo debía encontrar alguna respuesta para repensar la identidad del México antihispánico e independiente. La reafirmación honrosa y orgullosa de un pasado distante, tan distante como los horizontes preclásico, clásico y posclásico de la civilización mesoamericana, se convirtió así en el expediente privilegiado para avanzar sobre las deudas del pasado y hacia el encuentro de la identidad. Hasta el legendario Porfirio Díaz, que sería registrado en los anales de la historia oficial como dictador, proeuropeizante, anticampesino y, por lo tanto, antiindigenista, gustaba de pasear la identidad nacional en las ferias universales del siglo XIX, utilizando para el caso la construcción de un pavellón que se edificaba a imagen y semejanza de las pirámides aztecas (TENORIO, 1994). Este nacionalismo reconfirmado en lo indio, que paradójicamente desprecia a los indios, prevalece crítica o ingenuamente como uno de los abrevaderos más estimulantes y enigmáticos en el que continuan bebiendo los más grandes pesadores del siglo $\mathrm{XX}^{8}$. En contraparte, la ausencia de este nudo en la configuración nacional

\footnotetext{
${ }^{7}$ Para una evaluación del carácter estructuralmente colonial de la cultura en México y de sus repercusiones en la vida política y económca nacional, puede leerse com provecho el estupendo libro México profundo. Una civilización negada (BONFIL, 1986).

${ }^{8}$ El ejemplo por excelencia para esta afirmación es ni más ni menos que El laberinto de la soledad, del premio Nóbel Octavio
} 
brasileña es tan evidente que, aún, hoy, depués de la conmemoración del quinto centenario del "descubrimiento" de América, la historia de los libros de texto marca el fin de la prehistoria en el 1500, esto es, con la llegada del occidente luso. La considerable debilidad de un horizonte de significaciones autóctonas remotas o la renuncia a él para reflexionar la cultura y realidad brasileñas es, sin duda, un sesgo distintivo entre la trayectoria del pensamiento político social de ambos países?.

Si el estado de lo indio precisaba de una reelaboración para contemplar con pertinencia los problemas de la realidad nacional, la historia se había encargado de perpetuar tal herencia a través del mestizage cultural y poblacional. Es a través de este mestizaje convertido en mito fundante de la unidad nacional y del espíritu patriótico que se abrieron las puertas por las que discurrirían las respuestas a la problemática de la identidad nacional. Una vez que el legado prehispánico superó la postración de su confinamiento al estatus de una cualidad perniciosa pero inevitable y que fue reconocido no sólo como un hecho, sino en su derecho de participar en la construcción del futuro nacional ${ }^{10}$, se planteaba el dilema de dilucidar la cuantía y calidad de su intervención, es decir, el peso

Paz. Un ejemplo que antecede e influencia el pensamiento de Paz al respecto puede encontrarse en El perfil del hombre y la cultura en México, de Samuel Ramos (1934).

${ }^{9}$ Para un lector mexicano no puede sino causar asombro el siguiente pasaje del pensamiento de Sérgio Buarque de Holanda: “...somos ainda hoje desterrados em nossa terra. Podemos construir obras excelentes, enriquecer nossa humanidade de aspectos novos e imprevistos, elevar à perfeição o tipo de civilização que representamos: o certo é que todo o fruto de nosso trabalho ou de nossa preguiça parece participar de um sistema de evolução próprio de outro clima e de outra paisagem". (HOLANDA, 1995, p. 31) (cursivas nuestras).

${ }^{10}$ En medio de un análisis sobre la imitación europea en el siglo XIX y sobre las tendencias a la autodenigración en México, específico que éste legado debia asumir y que se le debía otorgar en la costrucción del nuevo espíritu o de la nueva Raza Cósmica, para decirlo con José Vasconcelos. Del pensamiento político social del México posrevolucionario surgirían los ideadores del indigenismo estatal, también sus críticos, que plantearían el problema en términos de un drama histórico constitutivamente inescindible de la mexicanidad ${ }^{11}$; sin embargo, el mito fundante continuaba en pie, a saber, el mestizaje como un hecho incontrovertible. Es de llamar la atención, a manera de ejemplo de tal incontrovertibilidad, el hecho de que no existan en México estudios de discriminación racial, en la medida en que desde la obviedad del sentido común se coloca como un contrasentido el racismo dentro de la igualdad racial del mestizaje. La carga emotiva de este debate y las consecuencias humanas que aún implica lo mantienen en pie como un referente permanente para el pensamiento político social contemporáneo ${ }^{12}$, una vez más urgido para develar crudas realidades ahora expuestas en carne viva por el levantamiento zapatista en el estado de Chiapas. Sólo ocho años antes de que el fenómeno neozapatista cimbrara la conciencia nacional, a mediados de la década de los ochentas y casi setenta años después de que la revolución diera origen a la Carta Magna que

Ramos afirmaba lo siguiente, por oposición a quienes se empeñaban en encontrar la sustancia pura de la identidad nacional: "En consecuencia, es forzoso admitir que la única cultura posible entre nosotros tiene que ser derivada." (RAMOS, 1934, p. 7).

${ }^{11}$ Para estos episodios y en general para una historia del indigenismo en México, véase el trabajo clásico Los grandes momentos del indigenismo en México (VILLORO, 1986).

${ }^{12}$ En 1992 y con motivo del quinto centenario del "descubrimiento" de América, Carlos Fuentes volvió a sumergirse en búsqueda de la identidad, tras de El espejo enterrado, como se llamó su libro; sólo que en este caso su pretensión fue más ambiciosa y no contempló nada más la identidad mexicana, sino la latinoamericana y hasta la iberoamericana (FUENTES, 1993). 
cimentaría el pacto social del Estado posrevolucionario, Bonfil Batalla advertía sobre la persistencia perniciosa de un México imaginario (criollo) sobre los destinos negados del México profundo (indio), ambos encubiertos tras la cortina de un mestizaje aparentemente consolidado y archivado en los memoriales de la historia nacional (BONFIL, 1986, 9-17, 45-71).

De nueva cuenta, la sobrevivencia y reproducción en el continuo de la historia nacional de este escenario de problemas, como referente ineludible para reflexionar, comprender y asumir una macrovisión frente a la realidad del país, constituye un acento distintivo del pensamiento político social mexicano. Se podría alegar como pretensión de particularidad cuestionable el esgrimir una constante que, más allá de su especificidad nacional, resulta un punto obligatorio en el itinerario de la reflexión de cualquier país forjado en la combinación cultural entre civilizaciones diferentes; lo cual sería el caso de América Latina toda y muy nítidamente de Brasil. Una apreciación de tal especie desconoce las profundas diferencias que animan la lógica cultural interna de los procesos de mestizage en latinoamérica, suponiendo de alguna manera que el indio (indianidad) y el negro (negritud), con los universos de sentidos culturales que los acompañaban, son figuras intercambiables. El indio: desterrado en su propia tierra, cosmogónicamente derrotado, civilizatoriamente dominado, testigo del derrumbe de su horizonte cultural y del fin de la historia de su pueblo, sabedor de sus derechos sobre un espacio y tiempo que le fueron expropiados ( $C f r$. LEON PORTILLA, 1980, passim); el negro: arrancado de su tierra, arrebatado de las fuentes sociales que alimentaron su cosmogonía, individual o colectivamente dominado, portador y expansor de su horizonte cultural, sin derechos legítimos - al igual que los conquistadores - sobre un tiempo espacio que jamás le pertenecieron y de los que comenzaría a apropiarse desde su lugar de elemento subordinado de la estructura de dominación social ${ }^{13}$. El mestizaje de las sociedades con una gran densidad civilizatoria indígena o con una conjugación civilizatoria ajena al territorio geográficamente conquistado y casi del todo socialmente inventado, dieron lugar a idiosincracias nacionales, a humores identitarios genéricamente diferenciados: la carga de culpabilidad histórica, el sentido trágico de la vida y la percepción del futuro son sólo algunos de los elementos que divergen con nitidez según el proceso de mestizaje de que se trate $^{14}$. La deuda con los pueblos originarios y su civilización, y la forma como han de conciliarse los dos Méxicos de Bonfil Batalla permanecen en el aire como un referente distintivo del pensamiento político social posrevolucionario, que jamás podría haber encumbrado con repercusión social tesis tan atrayentemente brasileñas como la democracia racial de Freyre o el antropofagismo cultural de Oswald de Andrade.

El tercer hito que permanece como un referente de larga duración en el pensamiento político social mexicano se refiere a la asociación histórica, construida a lo largo del siglo XIX, entre nacionalismo, liberalismo y lo que puede ser denominado como una política de Estado progresista ${ }^{15}$. En 1810, tras del estandarte de la Virgen de Guadalupe y con el cura Miguel Hidalgo a la cabeza, se organizaron las mili-

\footnotetext{
${ }^{13}$ Sólo desde esta diferencia es posible entender una afirmación de Ruy Mauro Marini como la siguiente: “Quizá sólo en Brasil donde la colonización ya había cumplido la tarea de diezmar en gran escala a los grupos autóctonos y sentar las bases de la economía sobre la esclavitud africana - el racismo no llegaba a constituir un problema"(MARINI, 1994, p.29).

${ }^{14} \mathrm{Al}$ respecto, no deja de llamar la atención para un lector mexicano el maravilloso ludismo y la falta de sentido trágico contenidos en la obra Casa grande e senzala (introdução à história da sociedade patriarcal no Brasil), del gran pensador Gilberto Freyre.

${ }^{15}$ Para el tema de la formación del nacionalismo mexicano puede consultarse la obra de David A. Brading, Los orígenes del nacionalismo mexicano (BRADING, 1973).
} 
cias populares para conquistar la independencia de la Nueva España e inaugurar el ciclo de la flamante nación mexicana. La lucha por la independencia adquirió así el carácter, no sólo de una pugna entre las élites hispanas y criollas, sino de una conflagración con un acentuado protagonismo popular que asociaría en lo futuro dos elementos en un binomio de gran trascendencia en el campo de las ideas: el pueblo y la construcción de la nación. Otra muy distinta sería la historia, incluidas sus repercusiones de largo plazo en el pensamiento, de la independencia de terciopelo que daría a luz a Brasil en el período de la oleada descolonizadora y que le garantizaría al poder una saludable continuidad, sin disturbios para las instituciones patrias. En México, la independencia como una caja de Pandora recién encontrada y abierta arrojó a la calle las diferencias cobijadas bajo el resguardo del orden colonial: la inestabilidad y la guerra se fueron multiplicando tras la pugna por el proyecto de nación que debía regir los destinos de la patria ${ }^{16}$. Los liberales, republicanos y federalistas, frente a los conservadores, monárquicos y centralistas, protagonizarían los nuevos capítulos de la historia nacional, de los que los liberales saldrían vencedores. Las fuerzas conservadoras fueron expulsadas de nuevo al campo de la historia proscrita, la de los perdedores, de cara al avance implacable de una nación moderna y de un Estado modernizador-progresista.

La mitología y los referentes procreados por la revolución de independecia encontraron refuerzos: los liberales habían apelado al fervor patriótico, a la soberanía nacional, al pueblo, se organizaron en ejércitos de chinacos mal armados y peor pertrechados, y huyeron con la república a cuestas en la figura mí-

${ }^{16}$ Para consultar el período como para una historia general de México, la obra más socorrida es la Historia General de México publicada por el Colegio de México (COSÍO VILLEGAS, 1976). tica de Juárez y su carroza ${ }^{17}$; los conservadores, habían apelado a la tradición, a la superioridad del orden monárquico, a la intervención extrangera para someter a las huestes liberales y ofrecieron la patria bajo el ropaje de Imperio Mexicano a la disnastía de los Habsburgo, al Archiduque austriaco Fernando Maximiliano ${ }^{18}$. En esta construcción de significaciones imaginarias, que no por serlo dejan de ser contundentemente reales, conservadurismo, clericalismo, imperialismo y antipatriotismo quedaron inevitablemente vinculados, desterrados a la periferia de la política y expulsados de la cauda del pensamiento político social que gozaría de mayores repercusiones y reconocimiento. Hasta muy recientemente, en los tiempos inaugurados bajo el sello del neoliberalismo y su neoconservadurismo económico, era de notarse la ausencia de una tradición de pensamiento conservador con ecos sociales significativos ${ }^{19}$. El siglo XX y su intelectualidad posrevolucionaria son herederos fieles de tal sistema de asociaciones, que en el otro lado de la moneda hizo del liberalismo una ideología con tintes populares, del nacionalismo un referente anticonservador y progresista, y del Estado un orden laico de ideología nacional popular y un agente de la modernización nacionalista. El pensamiento político social posrevolucionario codificado en clave nacionalista, de un particular nacionalismo, presenta difi-

${ }^{17}$ La idealización simbólica de este período se encuentra maravillosamente retratada en la novela En la lejanía del tesoro, de Paco Ignacio Taibo II (1991).

${ }^{18}$ Los avatares de la vida de Fernando Maximiliano, en su flamante y efímero imperio, se encuentran recogidos con minuciosa precisión histórica en la extraordinaria novela Noticias del Imperio del Premio Nacional de Literatura Fernando del Paso (1987).

${ }^{19}$ Para un análisis del pensamiento conservador puede consultarse la obra El pensamiento de la reacción mexicana (GARCÍA CANTÚ 1952). 
cultades de asimilación desde una realidad como la brasileña, en la que la bandera nacional no encontró un vínculo sistemático con las causas democrático liberales o con las luchas populares y sociales, fermentando un dejo de rancio conservadurismo político que aún hoy permanece en el aire, asociando simbólicamente, en sentido inverso, el nacionalismo con el autoritarismo.

\section{Y la Revolución Reinventó la Historia... Tam- bién la que no Cambió}

El México moderno, al igual que el independiente y el liberal decimonónico, conquistó su pasaporte a la historia con el rostro de la guerra, con más de un millón de muertos, tras interminables polvaredas de campesinos levantados en armas y tras una confluencia temporal y contradictoria de intereses que terminaría dejando el país y su reorganización política nacional en manos de los rancheros del norte ${ }^{20}$. La importancia de tal acontecimiento, como hecho fundante del nuevo Estado mexicano, no sólo impactó determinantemente el escenario del pensamiento político social, sino que fue minuciosamente cultivada y administrada por el régimen - pero no sólo por él - como un prodigio que permitia reinventar la historia patria, reconstruirla más nacional y más justa para la enorme mayoría que constituía ese ambiguo pero persistente sujeto llamado pueblo. Esta reinvención simbólica y material de la realidad produjo importantes efectos de ocultamiento y presentó como novedosas algunas cualidades que no harían sino fortalecer tradiciones

\footnotetext{
${ }^{20}$ Para las influencias intelectuales más importantes en el ámbito agrario, puede consultarse Precursores de la revolución agraria en México (HAMON y NIBLO 1976). Y en general, para un análisis del mapa intelectual que precedió y permeó el ideario y orientación de la revolución mexicana, es bien conocido el trabajo Los precursores intelectuales de la revolución mexicana (COCKCROFT 1971).
}

culturales de más largo plazo, ya enraizadas en la historia de los siglos precedentes ${ }^{21}$; además, el orden surgido de la revolución también vino aparejado con una serie de efectos que delinearían el escenario del pensamiento político social de este siglo y le imprimirían un sabor y una tonalidad particulares frente a sus equivalentes en buena parte de los países latinoamericanos. El pensamiento político social del siglo XX en México resulta difícilmente comprensible al margen de la sombra que la revolución mexicana proyectó sobré él y sobre la forma en que fueron organizados sus hábitos y procederes.

En el ritmo lento, centenario de las transformaciones culturales, el fenómeno de la revolución fortaleció el referente de lo nacional popular parido por el accidentado siglo XIX, pues si el mito-realidad de la unidad nacional había conquistado ya carta de legitimidad, el orden posrevolucionario admitiría en su estructuración política e ideológica una serie de contenidos populares sin precedentes en la historia nacional. La misma Constitución incorporaría como primicia mundial la idea del derecho social y el Estado haría incapié tantas veces como fuera necesario, no sólo en el terreno del discurso, a veces con políticas concretas como la reforma agraria, sobre el contenido popular de su pacto social fundante. La Nación, El Estado y El Partido - por antonomasia el que terminaría llamándose Partido Revolucionario Institucional (PRI) — se sumaban y resumían dando cuerpo a una sola fuerza, en un sólo orden social que en los hechos, en el discurso o por decreto representaba a todos los mexicanos ${ }^{22}$. Por supuesto, este nacionalismo social

\footnotetext{
${ }^{21}$ Para una de las críticas señeras sobre este proceso de reinvención monopólica de la historia, hechas desde el marxismo, puede consultarse La ideología de la revolución mexicana (CÓRDOVA 1973).

${ }^{22}$ Para un minucioso análisis de este proceso de institucionalización, la obra considerada clásica es de la autoría de Luis Javier Garrido, El Partido de la Revolución Institucionalizada (1982).
} 
y estatal reforzado, también sería renovado en la afirmación de sus contenidos progresistas, encontrando como espejo en la imaginación de la sociedad una caricatura de los rancios refinamientos proeuropeizantes de la élite porfirista y de su apertura económica al capital extrangero. A contracorriente del conservadurismo diízta, el Estado posrevolucionario organizaría a los obreros y campesinos, nacionalizaría las industrias del petróleo y la electricidad, implantaria una legislación laboral de avanzada, se opondría a los privilegios eclesiásticos e institucionalizaría la revolución, por lo que bien podía reivindicar para sí y para la nación su sentido, casi su destino, progresista $^{23}$. Por último, el fenómeno de la revolución no sólo fortalecería el mito-realidad de la unidad nacional y el carácter progresista de tal nacionalismo, también conferiría a la idea de revolución una cualidad y sentido radicalmente distintos de los que llevaría implícitos en el resto de América Latina. Desde el siglo XIX, los sucesivos órdenes sociales fueron producto de conflagraciones tumultuosas que enarbolarían su estirpe revolucionaria con orgullo y como fuente de legitimación; la gran revuelta social que marcara el traumático inicio del siglo XX prolongaría este fenómeno y lo llevaría a dimensiones desproporcionales: la revolución sería elevada al sumum de esencia nacional y de política de Estado; ser revolucionario no sólo no era un inclinación peligrosa y subversiva, era una obligación patriótica.

Este horizonte de continuidades históricas fortalecidas por la revolución mexicana proporciona algunas de las grandes coordenadas que permiten interpretar el escenario del pensamiento político social de este

\footnotetext{
${ }^{23}$ Resulta sintomático que los argumentos más utilizados por la Corriente Democrática, que produciría el sisma de 1988 en el PRI, apelaban a la pérdida del espíritu nacionalista y progresista de este instituto (Cfr. GARRIDO, 1994).

${ }^{24}$ Este techo ideológico, entre otras cosas, permitió que un
}

siglo y connotar alguna de sus peculiaridades que resulta de interés frente a otra realidad como la brasileña. Mientras el siglo XX mexicano transcurre en en el carril de una creciente institucionalización de la vida nacional, Brasil enfrentaría los traumáticos episodios de los vaivenes entre una modernización política democratizante y la perseverancia de tentaciones autoritarias y de la dictadura. Las condiciones para construir un pensamiento crítico, democrático, de corte liberal o revolucionario, e incluso el significado mismo del pensamiento revolucionario, serían muy distintos en ambos países. Indicada la pertinencia de tal distinción como una fuente para identificar diferencias en sus desarrollos nacionales, aquí cabe adelantar sólo en la materia en que se cuenta con alguna competencia, es decir, sobre las peculiaridades que al respecto distinguirían al pensamiento mexicano. Además de la supremacía de la nación como un macro alineamiento para reflexionar críticamente la realidad desde el supuesto inamovible de los intereses mayoritarios y de la soberanía - alimentaria, política, económica, etc -, una de estas singularidades fue la existencia de un ambiguo techo ideológico revolucionario al interior del cual convivían liberales revolucionarios, conservadores revolucionarios, marxistas revolucionarios y nacionalistas revolucionarios, que no eran necesariamente liberales, conservadores o marxistas, pero enarbolaban el ideario institucionalizado de la revolución mexicana ${ }^{24}$. Muchos de ellos compartían sin menoscabo de sus inclinaciones ideológicas la institucionalidad emanada de la revolución e incluso a ella se debían o en ella se desempeñaban,

reputado marxista latinoamericano como Haya de la Torre entablara cordiales relaciones con el régimen de la revolución y fuera más lejos intentando copiar en Perú, y a través del APRA, la estructura del PRI. Tiempo después, los sandinistas y su revolución triunfante analizarían la posibilidad de repetir, en Nicaragua, el intento fallido de Haya de la Torre. 
mientras que el régimen promovía sus obras o sus personas en tanto que herederos todos de la gran revolución mexicana ${ }^{25}$. Es difícil encontrar pensadores ya consagrados que no sean o no hayan sido revolucionarios en alguno de los múltiples sentidos que esta expresión admitía en México y de ello ni siquiera es posible exceptuar casos extremos como el de Gómez Morín, gran pensador que entre alguno de sus haberes tiene el de la fundación e intensa promoción del Partido Acción Nacional, o el de Octavio Paz, premio Nobel de literatura y hace tiempo referente obligado para el pensamiento conservador mexicano (KRAUZE,1985, p. 74-103; y KRAUZE, 1983, p. 124-168). Otra peculiaridad más, derivada de la intensa actividad de creación institucional del orden posrevolucionario en todos los ámbitos y muy importantemente en el de la cultura, es la predominancia indiscutible dentro del pensamiento político social de lo que podría denominarse como un razgo de visión social progresista de izquierda, con toda la ambigüedad que puede caber en tal calificativo, pero con la evidencia a favor del carácter marginal, cada vez menos, por cierto, de una corriente significativa y permanente de pensamiento conservador.

El orden surgido de la revolución mexicana no sólo fortalecería tradiciones culturales de largo alcance, la forma en que fueron institucionalizadas material y simbólicamente la política y la vida nacional, también acarrearía considerables efectos sobre el pensamiento político social de este siglo. Esta institucionalización arroja un mapa ambiguo de ordenaciones en el pensamiento político social mexicano,

\footnotetext{
25 Octavio Paz, en El ogro filantrópico, caracterizaría esta tolerancia ideológica por la existencia de un partido de Estado, en el que las diferencias ideológicas eran menores frente a las coincidencias en seno de la institucionalidad revolucionaria, incluido el PRI; Paz opone este fenómeno al de los Estados de partido, como
}

que difícilmente admitiría las mismas coordenadas pertinentes para países, como Brasil, en los que el referente del poder y el vínculo de la intelectualidad con dicho poder podría admitir como evidencia común connotaciones positiva o negativamente generalizadas. Lo primero sería la enorme dificultad del pensamiento político social mexicano para relacionarse crítica y lúcidamente con un Estado cuyo perfil histórico resultaba de gran complejidad y ambigüedad: ni democrático ni dictatorial, no socialista pero de alguna manera socializante, capitalista pero con contenidos populares que no se le podían escatimar sino echando mano de la ceguera, autoritario pero con un nivel de legitimidad envidiado por propios y ajenos, demagógico pero siempre dispuesto a conceder, homogeneizante y excluyente mas solícito para incorporar y tolerar la diferencias organizadas en su seno. La agudeza de Octavio Paz capturó y expuso plásticamente estas ambigüedades con la pericia y la economía de lenguaje de un hombre de letras. En una frase, en dos palabras: ogro filantrópico ${ }^{26}$. Una contradicción en términos que expresaba las bondades y mezquindades del Estado mexicano. Muchos años después, frente a la avalancha de transformaciones y privatizaciones neoliberales, la izquierda se vio obligada a reevaluar algunas de las características de ese viejo Estado y a emprender defensas que algunos años antes hubieran sido consideradas como claudicantes.

Esta no fue la única dificultad que complicó el escenario del pensamiento político social, también el espectro ideológico asumiría una ambigüedad expli-

el de la ex-Unión Soviética, en el que la ideología del partido era absolutizada y las diferencias en tal materia se convertían en asunto de vida o muerte.

${ }^{26}$ Perfectamente, la idea del ogro filantrópico puede ser interpretada como la personificación del Estado mexicano. 
cable por consideraciones arriba expuestas; dicho espectro quedaría dividido entre prorevolucionarios, lo que eso significara, y conservadores antirevolucionarios. Los enemigos podrían ser por igual cristeros clericales que comunistas radicales, ambos eran antirevolucionarios en el sentido de rebeldes al régimen emergido de la revolución. Así, alineaciones ideológicas que servirían para configurar un mapa del pensamiento político social en otros países, en México resultarían relativamente inoperantes, al grado de que aún los más grandes pensadores y críticos, aquellos cuyas obras son clásicas hace tiempo y sus tesis siguen animando el pensamiento inconforme de las nuevas generaciones, fueron o han sido hombres del régimen. Ser hombre del régimen admitía una relación tan relajada y ambigua como el acuerparse al interior de las instituciones revolucionarias, por lo que esta pertenencia no exigía un compartamiento partidario ni imponía limitaciones rígidas al quehacer intelectual de la crítica, siempre que ésta no se convirtiera en práctica política. Sin connotación peyorativa ni menoscabo a la calidad y trascendencia de sus ideas, Alfonso Reyes, José Vasconcelos, Antonio Caso y Alfonso Caso, Gómez Morín, Lombardo Toledano, Jesús Silva Herzog, Octavio Paz, Torres Bodet, Carlos Fuentes, Guillermo Bonfil Batalla, Fernando Benítez, Flores Olea, Gonzales Pedrero, y muchos otros, fueron y han sido en algún momento de sus vidas hombres del régimen, esto es, embajadores, consejeros o funcionarios públicos de importancia, pero no necesariamente ideólogos, aunque de éstos también los hubo y de excepcional calidad como Don Jesús Reyes Heroles. Hasta los Contemporáneos, primeros grandes iconoclastas del México moderno y pares de los modernistas brasileños y su Paulicéia Desvairada, encontraron apoyo a sus publicaciones en la institucionalidad revolucionaria ( $C f r$. SHERIDAN, 1985). El ogro filantrópico tenía un corazón muy amplio, dispuesto a cobijar a aduladores e inconformes, pero no perdonaba la traición y la cobraba con precio de muerte a quienes trataban de emanciparse de su tutela. Descontadas tolerancias y permisividades a la mexicana, la enorme fuerza de gravitación que ejercía el Estado en la vida nacional no fue la menor de las dificultades que accidentaron el camino para la maduración de un pensamiento político social crítico, pues si por un lado el Estado era un intenso promotor cultural, por el otro absorvía e incorporaba todas las expresiones sobresalientes de inteligencia y juicio independiente (Cfr. CAMP, 1988; y CAREAGA, 1971). Aún hoy en día, el tránsito de la fama académica a las posiciones de gobierno es un expediente de uso frecuente y permanece como un elemento disruptor de las condiciones de continuidad que favorecen el madurecimiento y recreación de las tradiciones de pensamiento.

\section{Retratos de Familia... Instantáneas Selectivas de una Tradición Prolija}

Un siglo contiene demasiados años, demasiadas vidas dedicadas a reflexionar la realidad y a repensar la tradición, muchos esfuerzos que alcanzaron famas efímeras y otros que aún están por ser redescubiertos y revalorados, muchas obras voluminosas o minúsculas que trascendieron por razones de difícil evaluación, no siempre relacionadas en primer grado con la complejidad o profundidad del pensamiento. Si esto no fuera dificultad suficiente, estas vidas, esfuerzos y obras no son homogéneas ni fáciles de ordenar con criterios nítidos, ni aún tratándose de los trabajos de un sólo autor: desde porque tuvo una existencia fugaz y su pensamiento fue interrumpido precozmente, hasta porque la longevidad y la escritura abundadante le dieron tiempo de producir en demérito de su propia trayectoria. Escollos de este género encuentran una forma de hacerles frente en los estudios de generaciones, pero aun en tales abordages los traslapes temporales, la ubicuidad de ciertos pensadores y la difícil catalogación de otros, persisten impunemente 
al intento de toda sistematización ${ }^{27}$. En este caso, se aspira a mucho menos, simplemente a completar el recorrido del panorama hasta aquí avanzado con referencias y características más puntuales que permitan corroborarlo y enriquecerlo; nada más que destacar a la manera de una introducción, y de forma por fuerza fragmentaria, los grandes referentes del pensamiento político social de este siglo en México; tan sólo dar algunas indicaciones y formular un convite para profundizar en la obra de estos hombres de letras que dejaron un profundo impacto en la vida cultural del país.

Para dar cabida a tal propósito se echará mano de un corte arbitrario pero orientador, que facilitará a grandes razgos una ubicación histórico temporal de los autores escogidos. Se trata de tres instantáneas que abarcan igual número de períodos: una de los pensadores que anteceden a la década de los cuarentas y que cuentan ya en sus registros personales con el impacto de la revolución de 1910, a los que podría denominarse padres de la prolija familia de pensadores mexicanos; otra de aquellos que surgieron a la luz pública entre los cuarentas y los sesentas, una vez que el orden posrevolucionario se había institucionalizado y que ocuparían el lugar de los hijos; y una última de los nietos, de los que aún dominan mayoritariamente el escenario del pensamiento nacional, de aquellos que serían marcados por las convulsiones políticas de los sesentas y que pasarían a la historia marcados por

\footnotetext{
${ }^{27}$ Cómo ubicar, por ejemplo, la trayectoria de Octavio Paz que pertenecería a la llamada generación del 29, pero cuya obra, influencia e importancia se acrecentaron con el correr del siglo; cómo sincronizar la obra de Carlos Monsiváis con la generación del 68 , siendo que aventajaba en años y trabajos al resto de sus representantes más destacados. Señalar tal género de dificultades no atenta contra la probada utilidad de los estudios de generaciones, sólo destaca los problemas que cualquier enfoque tendría que enfrentar. Por lo demás, el abordage por generaciones supone una especialización y profundidad de conocimientos biográficos
}

el 68 estudiantil y la matanza de Tlatelolco. Aún no se cuenta con un nuevo bloque de pensadores lo suficientemente diferenciado como para definir un relevo cultural y, sin embargo, es de esperarse que éste venga en camino y que esté luchando por el desplazamiento de los nietos del siglo XX, algunos de los cuales cuentan con edad avanzada y aspecto venerable. El relevo cultural dará a luz un nuevo bloque seguramente marcado por el desmoronamiento de la institucionalidad revolucionaria, por décadas de crisis, de internacionalización y por la incertidumbre sobre el futuro; quizá adquiera carta de legitimidad bajo la potestad del nuevo siglo ${ }^{28}$.

Las primeras décadas que sucedieron a la posrevolución reclamaron de un enorme esfuerzo constructivo y del concurso de los hombres más preparados para realizarlo: organismos públicos, leyes, organización política, ideas fuerza para convencer sobre los nuevos caminos que debería tomar la vida nacional, en fin, mucho por crear y otro tanto por rescatar desde una óptica más afín con el espíritu de los tiempos que corrían. En el pensamiento político social anterior a los cuarentas se distinguen hombres y vidas comprometidas con este esfuerzo de creación, por igual vinculados al quehacer intelectual que a los empeños de la nueva vida institucional; también aparecieron los primeros críticos de los caminos y perfiles que dicha institucionalización iría adoptando. En

muy superiores a la competencia de quien esto suscribe. En este campo se pueden consultar trabajos de reconocido prestigio y estilo como los del historiador Luis González y González, La ronda de las generaciones (1986).

${ }^{28}$ Existen algunos intentos por indagar el perfil de esta generación de relevo, bastan los nombres de su bautizo público para alimentar la intuición de lo que podrían ser sus contenidos: generación " $\mathrm{X}$ ", hijos de la crisis, generación perdida, generación quebrada. Lo poco que existe al respecto se mantiene en un carácter y formato periodístico y puede encontrarse en publicaciones mexicanas como Etcétera y Nexos. 
este terreno es posible distinguir las primeras grandes figuras señeras, pensadores ya maduros que de alguna manera fueron referentes obligatorios de las nuevas generaciones cuya consolidación cuajaría en el seno de la nueva institucionalidad. De aquellas grandes figuras cabe destacar en primer orden a tres pilares del pensamiento mexicano: Alfonso Reyes, polígrafo de muchos géneros y de un sinnúmero de materias, afortunado portador de una de las prosas más refinadas de la literatura nacional, uno de los hombes de letras más universales que hayan prohijado las tierras mexicanas y a la sazón Embajador de México en Brasil y traductor entusiasta al español de la poesía en lengua portuguesa ${ }^{29}$; José Vasconcelos, embajador cultural de México en América Latina, Secretario de Educación Pública, filósofo, incansable dilucidador de la identidad nacional y latinoamericana a travéz de su idea de la Raza Cósmica, convencido promotor de su misión histórica a la manera de un Ulises criollo, como el mismo gustó de designarse en la escritura de sus memorias, y protagonista central de la primera gran ruptura intelectual contra el régimen de la revolución, cuando postuló su candidatura a la presidencia de la república en contra del partido oficial ${ }^{30}$; por último, Antonio Caso, el gran maestro, filósofo e intelectual de corte más académico, también preocupado por la esencia nacional y convencido de su misión educativa ${ }^{31}$. Los tres fueron poseedores de un pensamiento en el que aún no se diferenciaba del todo la política de la academia y estas de la filosofía o de las letras ( $C f r$. VILLEGAS, 1988), los tres abrazaron el ensayismo como género para ordenar y exponer su pensamiento, los tres

${ }^{29}$ La obra completa de Alfonso Reyes, en sus cuantiosos volúmenes, se encuentra publicada por el Fondo de Cultura Económica.

${ }^{30}$ Sus dos obras más conocidas son el: Ulises Criollo y, por supuesto, La raza cósmica (VASCONCELOS, 1958 y 1948). fueron hombres del régimen y, por supuesto, los tres fueron hombres de letras. Estos pensadores encontrarían su posible equivalente brasileño en la obra de un Gilberto Freyre y, sin embago, es de llamar la atención que aún con ese maravilloso sabor literario que distingue la obra de este último, su pensamiento se encuentre formulado en términos de un rigor académico, según los cánones de la época, que no encuentra parangón en México. En segundo orden y como sus herederos inmediatos o remotos, según afinidades y proximidades cronológicas, habría que mencionar a Vicente Lombardo Toledano, Manuel Gómez Morín y Alfonso Caso, dentro de los más próximos ${ }^{32}$. Sin la estatura literaria de sus antecesores, los dos primeros continuaron privilegiando el ensayismo y el último adoptó un perfil más académico, de historiador y antropólogo. Particular mención merece el hecho de que, por un lado, Vicente Lombardo Toledano se invistió como uno de los máximos expositores de un marxismo a la mexicana, nacionalista, institucional y revolucionario - también a la mexicana -, mientras Goméz Morín terminaría por convertirse en fundador del partido del conservadurismo nacional, el PAN. Aún así, todos fueron hombres del régimen.

Dentro de los pensadores más distantes, tanto en afinidades como cronológicamente, desfila un repertorio mayor de nombres y obras: Lucio Medieta y Nuñez, Jesús Silva Herzog, Samuel Ramos, Manuel Gamio, Fernando Benítez, Edmundo O'Gorman, Leopoldo Zea y muchos más; pero sin duda, las figu-

${ }^{31}$ El pensamiento filosófico del maestro Antonio Caso puede encontrarse en su trabajo Positivismo, neopositivismo y fenomenología y para una muestra más general puede consultarse con provecho su Antología filosófica (CASO, 1941 Y 1985).

${ }^{32}$ Un análisis de su pensamiento como integrantes del grupo de los siete sabios puede encontrarse en la obra los Caudillos culturales de la revolución mexicana, del afamado historiador Enrique Krauze (1985). 
ras más controvertidas, aquellas que más profunda hueya, que más hondo calarían en el pensamiento nacional por su vocación crítica, siempre irrestricta e infatigable, por su mirar mordaz y agudo, y por su ejercicio permanente de independencia intelectual, fueron el grupo de pensadores aglutinados bajo el apelativo los Contemporáneos y dos pensadores de andar solitario: José Revueltas y Octavio Paz. Con el tiempo, este último conquistaría niveles de reconocimiento que lo llevarían en los brazos de la fama al mundo entero y le otorgarían el premio Nobel de Literatura por una extensa obra poética y ensayística, en la que plasmó sus reflexiones sobre los ámbitos más variados de la cultura univesal y de la vida nacional. Hasta el día de hoy permanecen como referentes plenos de sentido sus interpretaciones versátiles y heterodoxas sobre la identidad de lo mexicano, la cultura política, la historia y sociedad nacionales, y el Estado que todo quiso cristalizar dentro de su orden posrevolucionario ${ }^{33}$. Otra muy distinta sería la suerte de José Revueltas, irreverente, crítico, expulsado de las filas del Partido Comunista Mexicano, fundador del espartaquismo e igualmene arrojado de su seno por sus inconformidades nunca silenciadas, obsesivo pensador de las particularidades de un Estado que devoraba y asimilaba el discurso de la izquierda y se decía revolucionario, analista caústico de la izquierda - de su ortodoxia acrítica y de sus posiciones frente al Estado - condenado al olvido por sus colegas de causa y por un régimen en el que, pese a su laxitud, no tenía cabida; en fin, raro ejemplo de independencia y autonomía de criterio de una igualmente rara izquierda militante que se negó a sucumbir frente a las rigideces ideológicas tan propias del extinto mundo de

\footnotetext{
${ }^{33}$ Además de las obras ya referidas (El ogro... y El laberinto...), vale la pena mencionar Posdata, disponible bajo diversos sellos editoriales.
}

la guerra fría ${ }^{34}$. Paradógicamente, los vaivenes de su vida lo hicieron ejemplo testimonial para las generacions de jóvenes que protagonizaron el movimiento estudiantil del 68 y le devolvieron un reconocimiento de su importancia como referente en el pensamiento político social mexicano. Años después, el movimiento estudiantil de mediados de los ochentas aún evocaba su presencia en el garabateo de una pinta: "Hay José, cómo me acuerdo de ti en estas Revueltas". El ensayo fue el género privilegiado para exponer su pensamiento, pero no todo ni la mayor parte fue crítica política, también fue conocido como crítico literario y cinematográfico, como novelista y dramaturgo. Al respecto, ni qué decir de los Contemporáneos, hombres de letras inclinados a la poesía, filosofantes, ensayistas y con la crítica como sello distintivo de un grupo particularmente heterogéneo; grupo de una composición tan flexible que la enumeración de sus integrantes sucita polémica, aunque indudablemente exista acuerdo e torno a sus figuras más representativas: Jaime Torres Bodet, Xavier Villaurrutia, José Gorostiza, Enrique Gonzales Rojo, Gilberto Owen, Salvador Novo y Jorge Cuesta ${ }^{35}$. En el México de hoy, el quehacer literario e intelectual - no académicamente especializado - resulta difícilmente concebible al margen de la influencia que dejaron sus obras e ideas.

Este mosaico, incompleto y lamentablemente injusto, bosqueja la herencia de los grandes fundadores, la carga recibida por las futuras generaciones de pensadores, aquellas que en uso de la analogía familiar ocuparían el incómodo sitio de hijos, frente a un mapa de referencias densamente poblado por la obra de sus

\footnotetext{
${ }^{34}$ Sus dos obras más pertinentes al caso son: Ensayo sobre un proletariado sin cabeza y México: una democracia bárbara.( REVUELTAS, 1980 y 1982).

${ }^{35}$ Para un análisis y recuento de la obra de los Contemporáneos, la referencia indisputada es de Guillermo Sheridan, Los contemporáneos (1985).
} 
antecesores. El pensamiento emergente entre las décadas de los cuarentas y los sesentas contó con la maduración de una vida institucional en los más diversos ámbitos, incluido el cultural con su enorme crecimiento de instituciones de educación superior, y gozó de las mieles de un crecimiento y estabilidad económica que ganarían el nombre de "el milagro mexicano". La bonanza de los mejores tiempos y la maduración institucional abrieron las puertas para la especialización del pensamiento político social y para el surgimiento y continuidad de un quehacer académico intelectual, crecientemente diferenciado por áreas de estudio y por vocaciones científicas, artísticas, periodísticas o políticas; habían quedado atrás los tiempos de aquellos viejos hombres letrados, políticos, fundadores de instituciones e ideas, tan particularmente característicos de la intelectualidad mexicana de las primeras décadas posrevolucionarias ( $C f r$. VILLEGAS, 1966). Dentro de un repertorio cada vez más amplio y diversificado, es posible destacar del escenario del pensamiento político social de este período, entre otros, los nombres de Carlos Fuentes ${ }^{36}$, Ricardo Garibay, Luis González y González, Miguel León Portilla, Pablo Gonzaléz Casanova, Guillermo Bonfil Batalla, Victor Flores Olea, Enrique González Pedrero, Jesús Reyes Heroles, Luis Villoro, Emilio Uranga, Francisco López Cámara, Gabriel Zaid, Jose Luis Ceceña, Rodolfo Stavenhagen, Alonso Aguilar, Eduardo Blanquel y Ernesto Lemoine. Los dos primeros continuarían con la tradición ensayística y literaria de los hombres de letras, el resto se incorporaría a los esfuerzos por el avance disciplinario en la sociología, historia, antropología y economía. Bonfil Batalla, Flores Olea, González Pedrero y Reyes Heroles

\footnotetext{
${ }^{36}$ El pensamiento político social de Carlos Fuentes permeó su obra literaria, si bien se encuentra específicamente expuestos en trabajos como: El campo mexicano, y Tiempo mexicano. Recientemente publicó su Nuevo tiempo mexicano y El espejo enterrado.
}

combinarían en su trayectoria las responsabilidades en la gestión administrativa pública, en puestos tan importantes como los de Gobernador o Secretario de Estado, con los rigores de la investigación político social e histórica y los esfuerzos libres e imaginativos del género ensayístico ${ }^{37}$. Desde la academia, el resto impactaría la tradición del pensamiento político social mexicano con obras ya clásicas como La democracia en México, de Gonzáles Casanova, México profundo: una civilización negada, de Bonfil Batalla, Los grandes momentos del indigenismo en México, de Luis Villoro, y las "Siete tesis equivocadas sobre América Latina", de Rodolfo Stavenhagen; esta última de repercusiones continentales ${ }^{38}$.

El fin del milagro mexicano y la multiplicación de una clase media, diligentemente prohijada bajo el amparo de la institucionalidad revolucionaria, marcarían un nuevo cuadro de crisis e insurgencia social organizada para demandar apertura al autoritarismo estatal y defender, de alguna manera, los privilegios de los que este sector social se suponía acredor sin garantía futura de su cumplimiento. Una nueva rebeldía, el divorcio intelectual y social de un Estado que insistía en institucionalizarlo todo bajo su éjida, la proliferación de las interpretaciones marxistas de la historia y realidad nacionales, y la mayoritaria subordinación del conocimiento y del quehacer intelectual al compromiso político emancipatorio, caracterizarían al horizonte de pensadores marcados por el traumático episodio de muertes y autoritarismo estatal que cortó de tajo la irreverencia estudantil el dos

\footnotetext{
${ }^{37}$ Ejemplos de los productos de estas trayectorias intelectuales son: La riqueza de la pobreza. Apuntes para un modelo mexicano de desarrollo, (GONZÁLEZ PEDRERO, 1979) y El liberalismo mexicano, (REYES HERÓLES, 1976).

${ }^{38}$ Este conocido ensayo de Stavenhagen registró repercusiones considerables en América Latina. Puede encontrarse publicado en el libro Sociología y subdesarrollo (STAVENHAGEN, 1972).
} 
de octubre de 1968. Estos pensadores serían el referente de las nuevas generaciones distanciadas del régimen revolucionario y permanecerían en su calidad de referentes orientando los sentires y pareceres de los jóvens que llegarían después, aquellos que adquirirían conciencia del mundo con el signo de la crisis económica y enmedio de lustros acumulativos de descomposición social y reformas neoliberales. Con la excepción notable y lamentable de Carlos Pereyra, ausente por los caprichos de una muerte precoz, los nombres de estos pensadores aún forman parte de la cotidianidad letrada: Carlos Monsiváis, Lorenzo Meyer, Arnaldo Córdova, Enrique Semo, Adolfo Gilly, Hector Aguilar Camín, Roger Bartra y Manuel Aguilar Mora, entre otros. Mosiváis, poseedor de uno de los registros más amplios en la crónica mexicana, sólo comparable con la tradición contenida en la obra de Salvador Novo, ha dejado pocos rincones de la vida nacional sin escudriñar en sus análisis siempre irónicos y mordaces, y más pocos aún son los pensadores que escapan a la influencia de sus ideas ${ }^{39}$. Los demás, historiadores, analistas políticos y ensayistas de notable calidad, fundaron los nuevos mirares de la historia mexicana, por fuerza y por fortuna disruptora de la alguna vez hegemónica historia oficial de la revolu-

\section{Referencias}

BONFIL BATALLA, Guillermo. México profundo. Una civilización negada. México, Grijalbo, 1986.

BRADING, David A. Los orígenes del nacionalismo mexicano. México, Sep., 1973.

${ }^{39}$ Dentro de sus obras destacan, para el efecto que aquí interesa: Dias de guardar y Entrada libre: crónicas de una sociedad que se organiza, ambas disponibles, como la mayor parte de su obra, bajo el sello de la casa editorial ERA (MONSIVÁIS, 1977, 1988)

${ }^{40} \mathrm{Al}$ respecto pueden mencionarse, a título de ejemplos ilus- ción y su régimen ${ }^{40}$. Su relevo cultural, se ha dicho ya, es un proceso que está por presenciarse.

El mundo de la llamada intelligentzia, con sus tentaciones, recurrencias y aversiones, es un campo estrecho de la vida social que, en ocasiones, asemeja entre sí a sus participantes de diversos contextos más de lo que podría aproximarlos a las formas de vida social propias de otros sectores de sus respectivas poblaciones nacionales. No obstante, las ideas, hábitos y prácticas de aquellos que se han distinguido por un trabajo intelectual, vienen preñadas de historia en el sentido más extenso de la palabra y se convierten a la vez que en un instrumento, en un espejo que refleja, más allá de los límites de la conciencia, la realidad que pretendían instrumentalizar explicativamente. Así, ensayistas por excelencia, literatos de notable factura, nacionalistas de distintos nacionalismos, revolucionarios de diverso cuño, los hombres de letras del siglo XX mexicano no sólo ofrecen una obra indispensable para comprender la realidad de este país, ellos mismos constituyen un espejo en el que es posible leer la historia y encontrar claves para enriquecer su comprensión. Cuanto mejor si este espejo proyecta un nuevo juego de luces y sombras sobre el desarrollo intelectual de una realidad compleja, tan distante y tan cercana como la brasileña.

CAMP, Roderic Ai. Los intelectuales y el Estado en el México del siglo XX. México, FCE, México, 1988.

CAREAGA, Gabriel. Los intelectuales y la política en México. México, Extemporáneos, 1971.

trativos, las siguientes obras: Arnaldo Córdova, El discursos de la revolución Mexicana; Adolfo Gilly, La revolución interrumpida; Hector Aguilar Camín, La frontera nómada; Roger Bartra, La jaula de la melancolía; Manuel Aguilar Mora, El bonapartismo mexicano; y Enrique Semo, Historia mexicana: economía y lucha de clases. 
CASO, Antonio. Positivismo, neopositivismo y fenomenología. México, UNAM, 1941. . Antología filosófica. México, UNAM, 1985.

COCKCROFT, James. Los precursores intelectuales de la revolución mexicana. México, S. XXI, 1971.

CÓRDOVA, Arnaldo. La ideología de la revolución mexicana. México, ERA,1973.

COSÍO VILLEGAS, Daniel. Historia General de México. T. I y II. México, Col. Mex., 1976.

ESCALANTE GONZALBO, Enrique. Ciudadanos Imaginarios. México, Col. Mex., 1991.

FUENTES, Carlos. El espejo enterrado. México, FCE, 1993. El campo mexicano. México, Joaquín Mortiz, 1884. Tiempo mexicano. México, Joaquín Mortiz, 1984.

GARCÍA CANTÚ, Gastón. El pensamiento de la reacción mexicana. México, Empresas Editoriales, 1952.

GARRIDO, Luis Javier. El Partido de la Revolución Institucionalizada. México, Siglo XXI, 1982. La ruptura. México, Grijalbo, 1994.

GONZÁLEZ, Luis González y. La ronda de las generaciones. México, Col. Mex., 1986.

GONZÁLEZ PEDRERO, Enrique. La riqueza de la pobreza. Apuntes para un modelo mexicano de desarrollo. México, Joaquín Mortiz, 1979

HAMON, James y NIBLO Stephen. Precursores de la revolución agraria en México. México, SEP 1976.

HOLANDA, Sérgio Buarque de. Raízes do Brasil. Brasil, Cia. das Letras, 1995.

KRAUZE, Enrique. Caras de la Historia. México, Joaquín Mortiz, 1983. Caudillos culturales de la revolución mexicana. México, Siglo XXI/ SEP, 1985.

LEÓN PORTILLA, Miguel. La visión de los vencidos. México, UNAM, 1980.

MARINI, Ruy Mauro y MILLÁN, Márgara. La teoría social latinoamericana. Los orígenes. México, El caballito, 1994.

MEYER, Jean y AGUILAR CAMÍN, Héctor. A la sombra de la revolución mexicana. México, Cal y Arena, 1991.
MONSIVÁIS, Carlos. Entrada libre: crónicas de una sociedad que se organiza. México, ERA, 1988. Dias de guardar. México, ERA, 1877.

"Notas sobre la cultura mexicana en el siglo XX". In: Cosío Villegas, Daniel. Historia general de México. T.II, México, Col. Méx., 1976, pp.1377-1548.

PASO, Fernando del. Noticias del Imperio. México, Diana, 1987. PAZ, Octavio. El laberinto de la soledad. México, FCE, 1992. El ogro filantrópico. España, Seix Barral, 1986.

RAMOS, Samuel. El perfil del hombre y la cultura en México. México, Imprenta Mundial, 1934.

REVUELTAS, José. Ensayo sobre un proletariado sin cabeza. México, ERA, 1980.

México: una democracia bárbara. México, ERA, 1982.

REYES HERÓLES, Jesús. El liberalismo mexicano. México, FCE, 1976.

SHERIDAN, Guillermo. Los Contemporáneos ayer. México, FCE, 1985.

STAVENHAGEN, Rodolfo. Sociología y subdesarrollo. México, Nuestro Tiempo, 1972.

TAIBO, Paco Ignacio. En la lejanía del tesoro. México, Oceano, 1991.

TENORIO, Mauricio. "Um Cuauhtémoc Carioca: Comemorando o Centenário da Independência do Brasil e a Raça Cósmica". In: Estudos Históricos, 14, 1994, pp. 123-148.

TODOROV, Tzevetan. A conquista da América. A questão do Outro. Brasil, Martins Fontes, 1993.

VASCONCELOS, José. Ulises Criollo. México, Jus, 1958. La raza cósmica. México, Espasa-Calpe, 1948.

VILLEGAS, Abelardo. Historia de la filosofía en México. Siglo XX. México, UAT, 1988.

. Autognósis: el pensamiento mexicano en el siglo XX. México, Instituto Panamericano de Geografía e Historia, 1985. La filosofía en la historia política de México. México, Pórmaca, 1966.

VILLORO, Luis. Los grandes momentos del indigenismo en México. México, Sep., 1986.

Endereço do Autor: R. Professor Carlos de Carvalho, 40 - apto. 121 • CEP 04531-080•São Paulo • SP • Brasil • E-mail: layda@usp.br 